\author{
Wacław Szcześniak \\ prof. dr inż. \\ Wydział Budownictwa i Architektury \\ Politechnika Lubelska \\ w.szczesniak@il.pw.edu.pl
}

DOI: 10.35117/A_ENG_17_09_06

\title{
Vibrations of thick plate resting on a deformable foundation under impulse load
}

\begin{abstract}
The paper deals with vibrations of thick plate resting on generalized Winkler's foundation. The plate is subjected to the impulse of force. Governing equations of the problem, analytical solution as well as numerical example are presented. Results of calculations are shownin the figures. Solution and diagrams are obtained by means of "Mathematica" code.
\end{abstract}

Keywords: Thick plate; Impulse of force; Generalized Winkler's foundation

The subject of considerations at work is the analysis of a rectangular elastic plate with an average thickness loaded with a Dirac force impulse. The plate rests on a generalized, twoparameter and three-dimensional elastic basis of the Winkler type taking into account the horizontal components of its reaction. The theory accepted for consideration is a variant of the known theory of Ambarcumian [1], where the deflection $w$ and two stress functions are introduced $\chi_{x}$ and $\chi_{y}$ [11]. In the general case, together with the disc effect, we deal with five movement equations defining three displacements $u, v$, and $w$ and two stress functions $\chi_{x}$ and $\chi_{y}$. By omitting the effect of vibrations in the middle plane of the plate, the so complicated system of five tenth order equations was limited to one fourth order equation describing deflection $w=w(x, y, t)$, and to the system of two conjugated equations describing the stresses $\chi_{x}$ and $\chi_{y}$. The load of the plate is a $S$ Dirac force impulse applied at any point on the upper surface. The board meets the boundary conditions of the articulated support on the perimeter, which also depend on the vertical and horizontal components of the substrate reaction described by the factors $k_{z}$ and $k_{t}$. The dynamic deflections of the plate have been determined analytically in the form of a double series. The results of the solutions are illustrated by graphs using the "MATHEMATICA" code.

\section{Plate motion equations}

Motion equations of a medium thickness plate can be derived in many ways, locally for example from kinetic equations or globally from the integral Hamilton principle.

Assuming the Winkler elastic foundation model described with two factors $k_{z}$ and $k_{t}$, depending on the mechanical properties and the thickness of the substrate layer [6]

$$
p_{z}=k_{z} w, \quad p_{t}=k_{t} u_{i}, \quad i=x, y,(1)
$$


horizontal and vertical forces on the lower plane are defined by expressions:

$\left[\begin{array}{c}X_{1} \\ Y_{1}\end{array}\right]=\frac{k_{t} h}{4}\left[\begin{array}{c}\frac{\partial}{\partial x} \\ \frac{\partial}{\partial y}\end{array}\right] w+\frac{k_{t} h^{3}}{24(1-v)}\left[\begin{array}{c}\chi_{x} \\ \chi_{y}\end{array}\right], \quad Z_{2}=p-k_{z} w,(2)$

where $w$ is the deflection of the central surface of the plate, and $\chi_{x}$ and $\chi_{y}$ they are some functions related to tangential stresses $\tau_{x z}$ and $\tau_{y z}$. Figure 1 shows a two-parameter, threedirectional substrate and a kinematic hypothesis referring to plate displacements. More details on assumptions regarding medium thickness boards are given in [11]. Functions $\chi_{x}$ and $\chi_{y}$ are related to angles $\beta_{x}$ i $\beta_{y}$, as in figure $\mathbf{1}$.
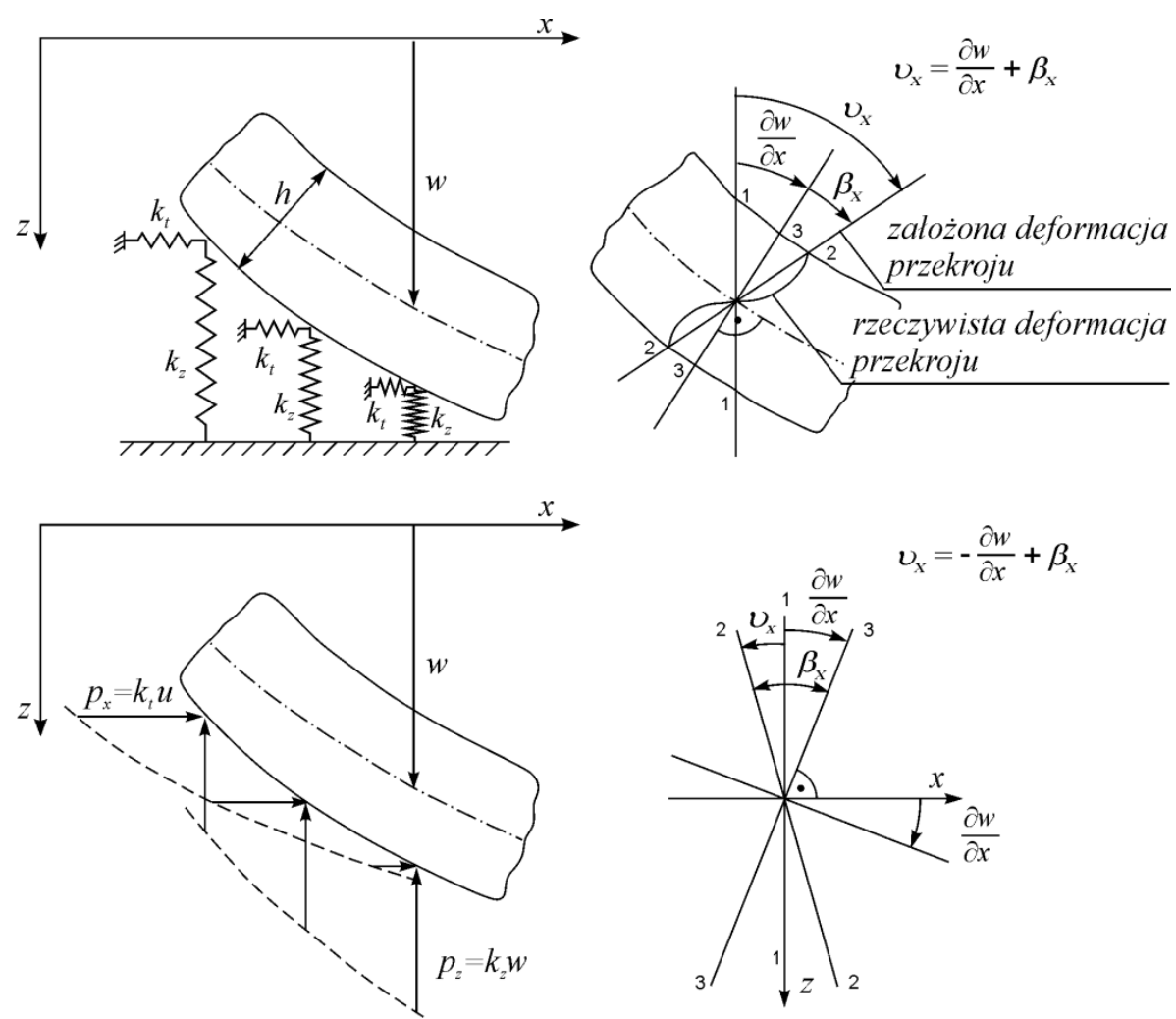

1. Medium-thickness plate on generic Winkler's three-way ground

As can be easily seen in figure 1, reactions of the generalized Winkler's substrate are both vertical and horizontal, so that friction between the bottom of the plate and elastic deformable substrate can be taken into account. Differential equations of motion, derived, among others in works [11], describing the dynamic deflection of a rectangular springboard, we write in the following way: 


$$
\begin{aligned}
& \nabla^{4} w+\frac{\rho h}{D} \frac{\partial^{2} w}{\partial t^{2}}-\frac{17-6 v}{60 D(1-v)} \rho h^{3} \nabla^{2}\left(\frac{\partial^{2} w}{\partial t^{2}}\right)+\frac{\rho^{2} h^{6}}{60 D^{2}(1-v)} \frac{\partial^{4} w}{\partial t^{4}}+ \\
& +k_{z}\left[\frac{w}{D}-\frac{(2-v) h^{2}}{10 D(1-v)} \nabla^{2} w+\frac{\rho h^{5}}{60 D^{2}(1-v)} \frac{\partial^{2} w}{\partial t^{2}}\right]+ \\
& -\frac{1}{1-\mu}\left\{\left[\frac{k_{t} h^{2}}{4} \nabla^{2}-\mu\left(\rho h \frac{\partial^{2}}{\partial t^{2}}+k_{z}\right)\right]\left[\frac{w}{D}-\frac{(2-v) h^{2}}{60 D(1-v)} \nabla^{2} w+\frac{\rho h^{5}}{360 D^{2}(1-v)} \frac{\partial^{2} w}{\partial t^{2}}\right]\right\}= \\
& =\frac{p}{D}-\frac{(2-v) h^{2}}{10 D(1-v)} \nabla^{2} p+\frac{\rho h^{5}}{60 D^{2}(1-v)} \frac{\partial^{2} p}{\partial t^{2}}+ \\
& +\frac{\mu}{1+\mu}\left[\frac{p}{D}+-\frac{(2-v) h^{2}}{60 D(1-v)} \nabla^{2} p+\frac{\rho h^{5}}{360 D^{2}(1-v)} \frac{\partial^{2} p}{\partial t^{2}}\right]
\end{aligned}
$$

where $\mu=\frac{k_{t} h^{4}}{24 D(1-v)}$ is a dimensionless coefficient describing the influence of unknown functions $\chi_{x}$ and $\chi_{y}$ for vertical forces occurring on the lower surface of the plate, $D=\frac{E h^{3}}{12\left(1-v^{2}\right)}$ is the flexural rigidity of the plate, it is the deflection of the plate, $\rho$ is the density of the material, $h$ is the thickness of the plate, and $p$ is the normal load to the horizontal center plane of the plate. It should be noted that the substrate coefficient $k_{t}$, in the plate motion equation, is included in the coefficient $\mu$, which is very small compared to one and can therefore be omitted, which is fully technically justified. If we accept then $\mu=0$, this basic equation of motion of the plate (3) is simplified and together with the equation describing torsional vibration is as follows:

$$
\begin{aligned}
& \nabla^{4} w+\frac{\rho h}{D} \frac{\partial^{2} w}{\partial t^{2}}-\frac{17-6 v}{60 D(1-v)} \rho h^{3} \nabla^{2}\left(\frac{\partial^{2} w}{\partial t^{2}}\right)+\frac{\rho^{2} h^{6}}{60 D^{2}(1-v)} \frac{\partial^{4} w}{\partial t^{4}}+ \\
& +k_{z}\left[\frac{w}{D}-\frac{(2-v) h^{2}}{10 D(1-v)} \nabla^{2} w+\frac{\rho h^{5}}{60 D^{2}(1-v)} \frac{\partial^{2} w}{\partial t^{2}}\right]+ \\
& -\left\{\left[\frac{k_{t} h^{2}}{4} \nabla^{2}\right]\left[\frac{w}{D}-\frac{(2-v) h^{2}}{60 D(1-v)} \nabla^{2} w+\frac{\rho h^{5}}{360 D^{2}(1-v)} \frac{\partial^{2} w}{\partial t^{2}}\right]\right\}= \\
& =\frac{p}{D}-\frac{(2-v) h^{2}}{10 D(1-v)} \nabla^{2} p+\frac{\rho h^{5}}{60 D^{2}(1-v)} \frac{\partial^{2} p}{\partial t^{2}}, \\
& \nabla^{2} \psi-\frac{10}{h^{2}} \psi-\frac{\rho h^{3}}{6 D(1-v)} \ddot{\psi}=0, \quad \psi=\frac{\partial \chi_{x}}{\partial y}-\frac{\partial \chi_{y}}{\partial x} .
\end{aligned}
$$

Assuming that $p=0, k_{z}=0$ and $k_{t}=0$ equations (4) determine the own vibrations of the plate without considering the substrate. Assuming harmonic, non-suppressed motion, functions $w$ and $\psi$ we will write the following patterns: 


$$
\begin{aligned}
& w=w(x, y, t)=\sum_{m=1}^{\infty} \sum_{n=1}^{\infty} A_{m, n}(t) \sin \alpha_{m} x \sin \beta_{n} y \cos \omega_{m, n} t, \quad \alpha_{m}=\frac{m \pi}{a}, \quad \beta_{m}=\frac{n \pi}{b}, \\
& \psi(x, y, t)=\sum_{m=1}^{\infty} \sum_{n=1}^{\infty} B_{m, n}(t) \cos \alpha_{m} x \cos \beta_{n} y \cos \omega_{m, n} t, \quad \lambda=\frac{a}{b}, \quad \beta=\frac{h}{a}, \\
& \gamma_{m, n}^{2}=h^{2}\left(\alpha_{m}^{2}+\alpha_{n}^{2}\right)=\pi^{2} \beta^{2}\left(m^{2}+\lambda^{2} n^{2}\right), \quad \gamma_{m, n}^{2}=\gamma_{m}^{2}+\gamma_{n}^{2}, \quad \gamma_{m}^{2}=h^{2} \alpha_{m}^{2}, \quad \gamma_{n}^{2}=h^{2} \alpha_{n}^{2}, \\
& \omega_{m, n}^{k l}=\pi^{2}\left(\frac{m^{2}}{a^{2}}+\frac{n^{2}}{b^{2}}\right) \sqrt{\frac{D}{\rho h}}=\frac{\pi^{2} \beta}{a}\left(m^{2}+\lambda^{2} n^{2}\right) \frac{c_{p}}{\sqrt{12}}=\frac{\gamma_{m, n}^{2} c_{p}}{h \sqrt{12}}, \quad m, n=1,3,5, \ldots
\end{aligned}
$$

In equations (5) $\omega_{m, n}^{k l}$ means the circular frequency of a rectangular plate determined according to the classic theory of Kirchhoff, whereas $c_{p}$ and $c_{s}$ mean respectively the longitudinal and transverse speed of the wave in the plate [6]:

$$
c_{p}^{2}=\frac{E}{\rho\left(1-v^{2}\right)}, \quad c_{s}^{2}=\frac{G}{\rho}, \quad c_{p}=c_{s} \sqrt{\frac{2}{1-v}} .
$$

By substituting the formulas (5) in the equation (4), we get three natural frequencies of the medium thickness plate stored in the following way:

$$
\omega_{m, n}^{(1,3)}=\frac{c_{p}}{h \sqrt{12}}\left\{\frac{1}{2}\left[P_{m, n} \pm\left(P_{m, n}^{2}-Q_{m, n}^{2}\right)^{\frac{1}{2}}\right]\right\}^{\frac{1}{2}}, \quad \omega_{m, n}^{(2)}=\frac{c_{p}}{h \sqrt{12}}\left[6(1-v)\left(10+\gamma_{m, n}^{2}\right)\right]^{\frac{1}{2}}
$$

where: $P_{m, n}=60(1-v)+(17-5 v) \gamma_{m, n}^{2}, Q_{m, n}=4 \gamma_{m, n}^{2}[15(1-v)]^{\frac{1}{2}}$.

In the case of a two-parameter substrate, the formulas (7) are complicated and are as follows:

$$
\begin{aligned}
& \tilde{\omega}_{m, n}^{4}-\frac{1}{12}\left(\frac{c_{p}}{h}\right) \tilde{P}_{m, n} \tilde{\omega}_{m, n}^{2}+\frac{1}{576}\left(\frac{c_{p}}{h}\right)^{4} \tilde{Q}_{m, n}^{2}=0, \\
& \tilde{P}_{m, n}=P_{m, n}+K_{m, n}, \quad K_{m, n}=\frac{k_{z} h^{4}}{D}\left(1+\frac{\theta \gamma_{m, n}^{2}}{24}\right), \\
& \tilde{Q}_{m, n}^{2}=4 \tilde{\gamma}_{m, n}^{2}[15(1-v)]^{\frac{1}{2}}, \\
& \tilde{\gamma}_{m, n}^{4}=\gamma_{m, n}^{4}+\frac{k_{z} h^{4}}{D}\left\{1+\left[\frac{2-v}{10(1-v)}+\frac{\theta}{4}\left(1+\frac{2-v}{60(1-v)} \gamma_{m, n}^{2}\right)\right] \gamma_{m, n}^{2}\right\}, \\
& \theta=\frac{k_{z}}{k_{t}}, \quad \mu=\frac{k_{t} h^{4}}{24 D(1-v)}, \quad \mu_{z}=\frac{k_{z} h^{4}}{D}, \quad \tilde{\gamma}_{m, n}^{2}=h^{2}\left(\alpha_{m}+\beta_{n}\right), \quad \lambda=\frac{a}{b},
\end{aligned}
$$


$\tilde{\omega}_{m, n}^{(1,3)}=\frac{c_{p}}{h \sqrt{12}}\left\{\frac{1}{2}\left[\tilde{P}_{m, n} \pm\left(\tilde{P}_{m, n}^{2}-\tilde{Q}_{m, n}^{2}\right)^{\frac{1}{2}}\right]\right\}^{\frac{1}{2}}$,

$\tilde{\omega}_{m, n}^{(2)}=\omega_{m, n}^{(2)}=\frac{c_{p}}{h \sqrt{12}}\left[6(1-v)\left(10+\gamma_{m, n}^{2}\right)\right]^{\frac{1}{2}}$, (c.d. 8)

$\tilde{\omega}_{m, n}^{(1)}<\tilde{\omega}_{m, n}^{(2)}<\tilde{\omega}_{m, n}^{(1,3)}$.

In the case of deflection and load, we seek the solution in the form of double series of own functions:

$w(x, y, t)=\sum_{m=1}^{\infty} \sum_{n=1}^{\infty} q_{m, n}(t) \sin \alpha_{m} x \sin \beta_{n} y, \quad p(x, y, t)=\sum_{m=1}^{\infty} \sum_{n=1}^{\infty} f_{m, n}(t) \sin \alpha_{m} x \sin \beta_{n} y$.

We write the load with force impulse in the following way, and divide the Dirac delta into a double series:

$p=p(x, y, t)=S \delta\left(x-x_{0}\right) \delta\left(y-y_{0}\right) \delta\left(t-t_{0}\right)$,

$\delta\left(x-x_{0}\right) \delta\left(y-y_{0}\right) \delta\left(t-t_{0}\right)=\frac{4}{a b} \delta\left(t-t_{0}\right) \sum_{m=1}^{\infty} \sum_{n=1}^{\infty} \sin \alpha_{m} x \sin \beta_{n} y \sin \alpha_{m} x_{0} \sin \beta_{n} y_{0}$,

$p(x, y, t)=S \delta\left(x-x_{0}\right) \delta\left(y-y_{0}\right) \delta\left(t-t_{0}\right)=\sum_{m=1}^{\infty} \sum_{n=1}^{\infty} f_{n, m}(t) \sin \alpha_{m} x \sin \beta_{n} y$,

$f_{n, m}(t)=\frac{4 S}{a b} \delta\left(t-t_{0}\right) \sin \alpha_{m} x_{0} \sin \beta_{n} y_{0} \sin \alpha_{m} x \sin \beta_{n} y$,

$\nabla^{2} p(x, y, t)=-\frac{4 S}{a b} \sum_{n} \sum_{m}\left(\alpha_{m}{ }^{2}+\beta_{n}{ }^{2}\right) f_{n, m}(t) \sin \alpha_{m} x_{0} \sin \beta_{n} y_{0} \sin \alpha_{m} x \sin \beta_{n} y$,

$\frac{\partial^{2} p(x, y, t)}{\partial t^{2}}=\frac{4 S}{a b} \sum_{n} \sum_{m} \ddot{f}_{n, m}(t) \sin \alpha_{m} x_{0} \sin \beta_{n} y_{0} \sin \alpha_{m} x \sin \beta_{n} y$.

Ultimately, we will get a fourth order equation for the unknown function $q_{m, n}=q_{m, n}(t)$. To simplify further entries, we will omit the 11 indicators in the formulas $m$ and $n$, writing for example $q=q(t)$ :

$$
\begin{aligned}
& q^{I V}+A \ddot{q}+\frac{1}{576}\left(\frac{c_{p}}{h}\right)^{4} Q^{2} q=\left\{\frac{2 S c_{p}{ }^{2}}{\rho h^{3} a b}[(1-v)+\right. \\
& \left.\left.+\tilde{\gamma}^{2}(2-v)-\frac{\rho h^{5} \alpha^{2} v^{2}}{12 D}\right]\right\} \delta\left(t-t_{0}\right) \sin \frac{m \pi x_{0}}{a} \sin \frac{n \pi y_{0}}{b},
\end{aligned}
$$

where: $\quad \theta=\frac{k_{z}}{k_{t}}, \quad \mu=\frac{k_{t} h^{4}}{24 D(1-v)}, \quad \mu_{z}=\frac{k_{z} h^{4}}{D}, \quad \tilde{\gamma}_{m, n}^{2}=h^{2}\left(\alpha_{m}+\beta_{n}\right), \quad \lambda=\frac{a}{b}, \quad \xi=\frac{h}{a}$, $\gamma=\pi \xi^{2}\left(1+\lambda^{2}\right), c_{p}{ }^{2}=\frac{E}{\rho\left(1-v^{2}\right)}, A=\left[60(1-v)+(17-6 v) \tilde{\gamma}^{2}+\mu_{z}\left(1+\frac{\theta \tilde{\gamma}^{2}}{24}\right)\right]$, 


$$
\hat{\gamma}^{4}=\left\langle\tilde{\gamma}^{4}+\mu_{z}\left\{1+\left[\frac{2-v}{10(1-v)}\right]+\frac{\theta}{4}\left(1+\frac{2-v}{60(1-v)} \tilde{\gamma}^{2}\right)\right\} \tilde{\gamma}^{2}\right\rangle, Q=4 \hat{\gamma}^{2}[15(1-v)] .
$$

The heterogeneous 4th order equation (11) was solved by computer with four zero initial conditions.

\section{Calculation example}

Equation (11) was solved analytically using the Wolfram "MATHEMATICA 10" package, also a series (9) programmed in this code.

In the example, the following geometric and physical figures of the board were adopted: $a=b=4 \mathrm{~m}, h=0,45 \mathrm{~m}, E=34 \mathrm{GPa}, \rho=2400 \mathrm{~kg} / \mathrm{m}^{3}, v=0,17$. The task was analyzed at different values of the elasticity coefficients of the substrate $k_{z}$ and $k_{t}$. The calculations were carried out in two cases of applying a pulse to the upper surface of the board: in its middle, i.e. at $x_{0}=\frac{1}{2} a, y_{0}=\frac{1}{2} b$ and near the corner of the plate at $x_{0}=\frac{3}{4} a, y_{0}=\frac{3}{4} b$.

Because the solution depends on a double series, which is slowly convergent, the calculation should take into account as many words as possible. The results of the calculations are illustrated by example drawings. Figures $\mathbf{2}$ and $\mathbf{4}$ show the deformation of the middle surface of medium-thickness slabs and their corresponding contour plans at the moment $t=\frac{1}{4} T_{1}$, where $T_{1}$ is the first, lowest period of natural vibration of the plate. Figure 3 shows the vibration diagram of medium-thickness medium on a three-directional substrate ( $k_{z}=k_{t}=150 \mathrm{MN} / \mathrm{m}^{3}$ )when load with impulse $S$ in the point with coordinates $x_{0}=\frac{3}{4} a$, $y_{0}=\frac{3}{4} b$. The chart has been drawn for the time interval $t \in\left\langle 0 ; 10 T_{1}\right\rangle$.

In addition, for comparison purposes, Figure 5 shows the charts of the Kirchhoff thin plate without taking into account the substrate, loaded with a single impulse near the corner of the plate [2]. Plate deflections on all charts are given in the dimensionless form and are a Green function. Due to the extensive scaling factor, we do not quote it here. A much simpler form has an analogous coefficient in the case of a thin plate on the basis of Własowa, obtained by the authors in the works [2]:

$$
\begin{aligned}
& \hat{w}=w \frac{b \pi^{2} \sqrt{D\left(\bar{m}+m_{0}\right)}}{4 S a}, \\
& w(x, y, t)=\frac{4 S}{\left(\bar{m}+m_{0}\right) \bar{m} a b} H\left(t-t_{0}\right) \times \\
& \times \sum_{m=1}^{\infty} \sum_{n=1}^{\infty}\left(\frac{1}{\omega_{m, n}} \sin \alpha_{m} x_{0} \sin \alpha_{n} y_{0} \sin \alpha_{m} x \sin \alpha_{n} y \sin \omega_{m, n} t\right) .
\end{aligned}
$$




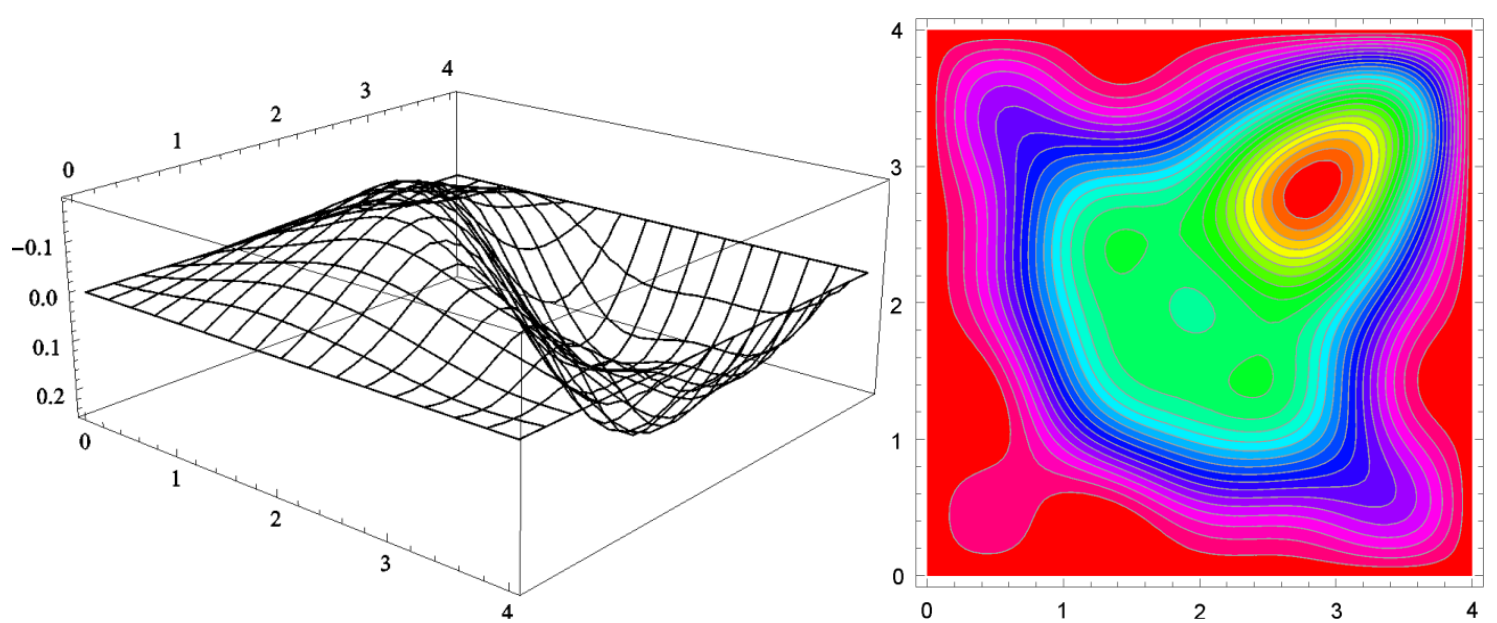

2. Distortion of the middle surface of medium-thickness boards on $S$ impulse impact near the corner of the plate $\left(x_{0}=\frac{3}{4} a, y_{0}=\frac{3}{4} b\right)$ at $k_{z}=k_{t}=150 \mathrm{MN} / \mathrm{m}^{3}$, moment $t=\frac{1}{4} T_{1}$, and the corresponding layout of the contours on the board

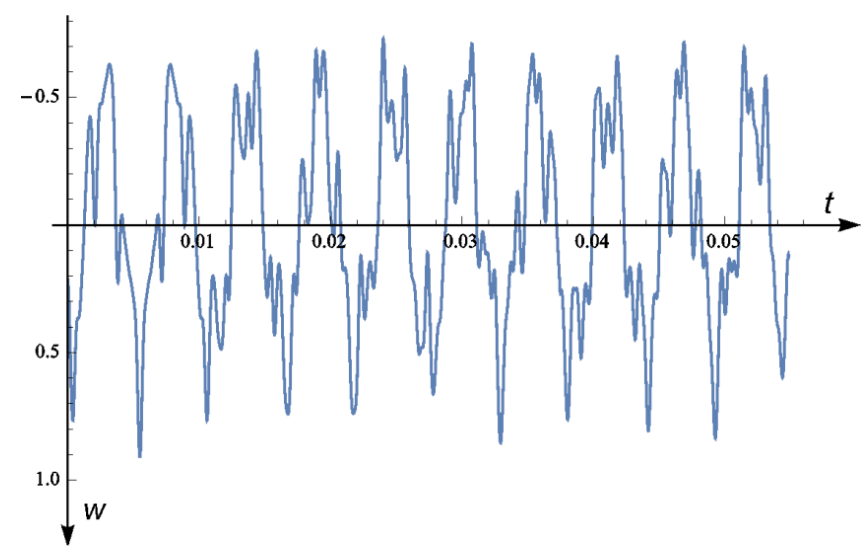

3. Medium plate vibration medium at $S$ impact near the corner of the plate $\left(x_{0}=\frac{3}{4} a, y_{0}=\frac{3}{4} b\right.$ ) at $k_{z}=k_{t}=150 \mathrm{MN} / \mathrm{m}^{3}$ in time $t \in\left\langle 0 ; 10 T_{1}\right\rangle$
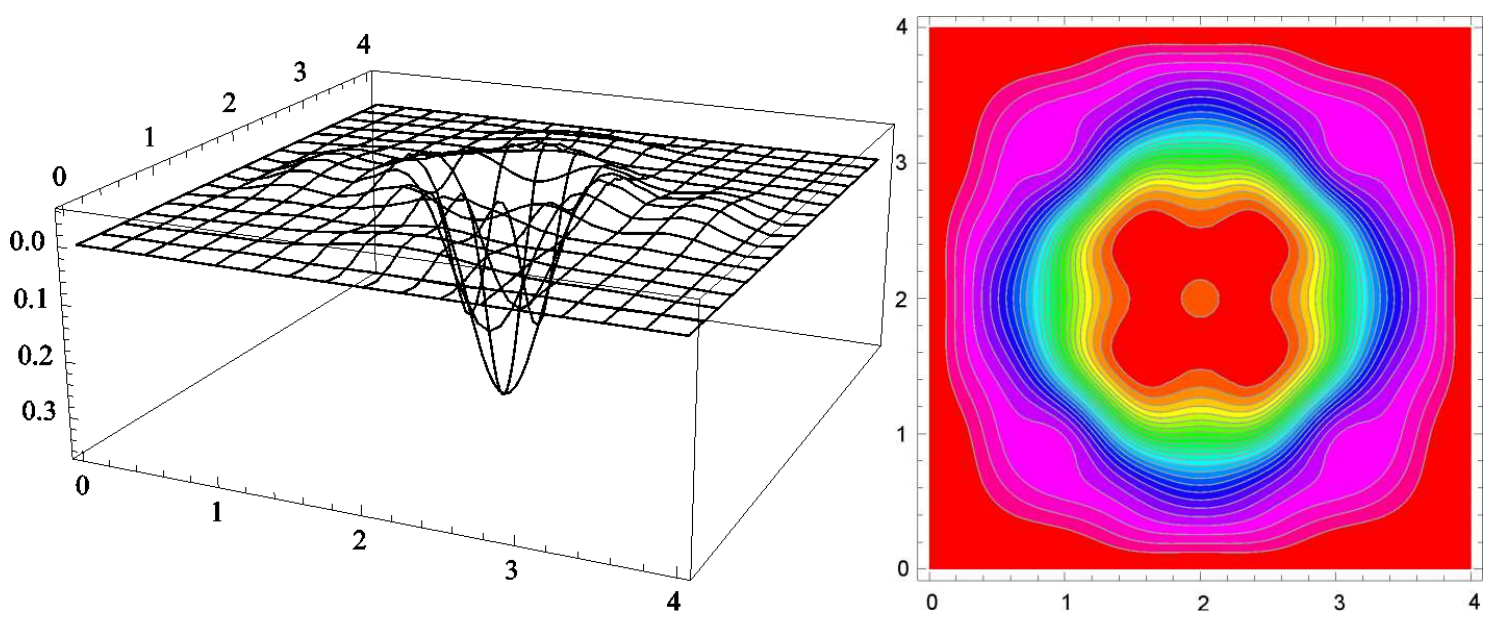

4. Distortion of the middle surface of medium-thickness boards on $S$ impulse impact in the middle of the plate at $k_{z}=150 \mathrm{MN} / \mathrm{m}^{3}$ i $k_{t}=0$, moment $t=\frac{1}{4} T_{1}$, and the corresponding contour layout 


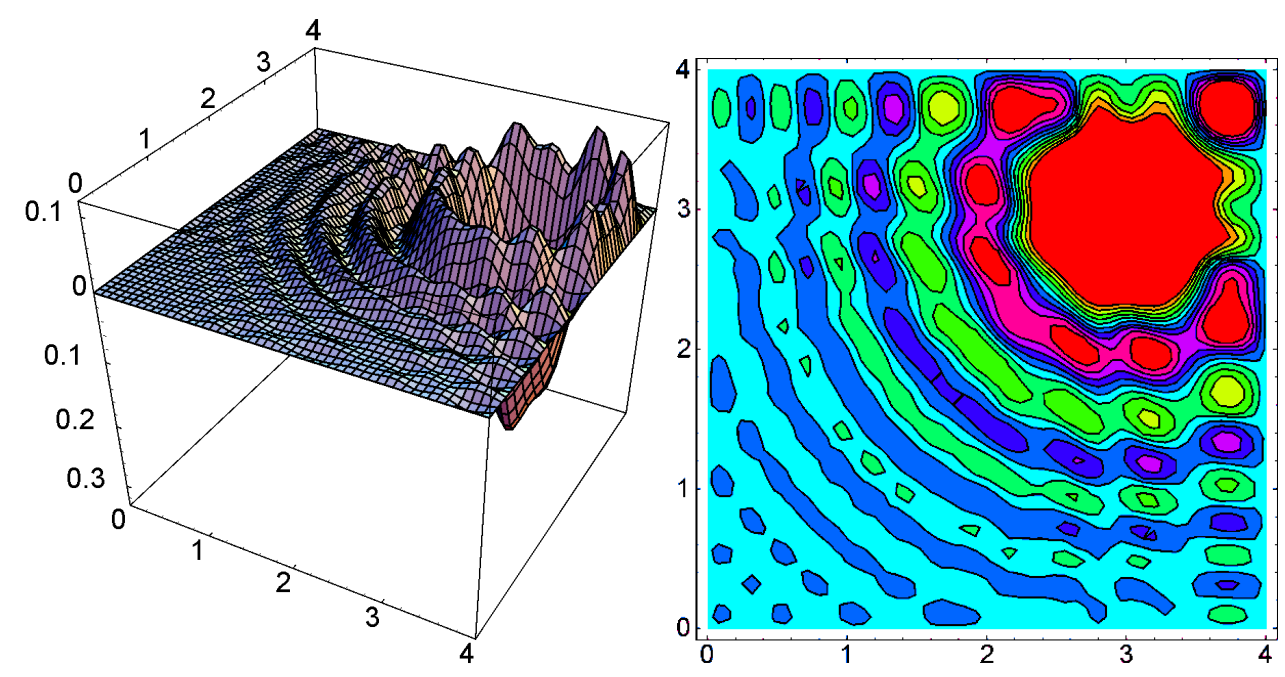

5. Distorted Kirchhoff plate, articulated on the perimeter, without substrate interaction, loaded with a single pulse at point $x_{0}=\frac{3}{4} a, y_{0}=\frac{3}{4} b$ and the corresponding contour layout [2].

\section{Summary}

The subject of discussion in this paper is a rectangular, elastic medium-thickness plate resting on Winkler's generalized three-directional spring substrate taking into account the horizontal components of its reaction. The delta pulse function The Dirac function operates at any point on the upper surface of the board. The dynamic deflections of the plate have been determined analytically in the form of a double series. Because this series is slowly convergent, the calculation should take into account as many words as possible. The dynamic deflections of the slab were analyzed. Using the deflection formula, you can also determine the internal forces and stresses in the plate. The load schema analyzed determines the so-called Green's function, used in other, more complex cases of real strokes on plates. The results of the study can be used to verify the impact model with the penalties in the MES. They can also be used by road builders who perform pavement strength tests with the FWD apparatus [4].

\section{Source materials}

[1] Ambarcumian S.A. Teorja anizotropnych płastin. Nauka, Moskwa 1987.

[2] Ataman M., Szcześniak W. Analiza ugięć płyty sprężystej Kirchhoffa spoczywającej na inercyjnym podłożu Własowa pod impulsem siły. Autobusy. Technika, Eksploatacja, Systemy Transportowe, Instytut Naukowo-Wydawniczy "Spatium", 2016, vol. 17, nr $12,537-540$.

[3] Ataman M., Szcześniak W. Drgania płyty sprężystej Kirchhoffa spoczywającej na inercyjnym podłożu Własowa wymuszone impulsem siły. Autobusy. Technika, Eksploatacja, Systemy Transportowe, Instytut Naukowo-Wydawniczy "Spatium", 2016, vol. 17, nr 12, 541-544.

[4] Krawczyk B., Mackiewicz P. Diagnostyka nawierzchni drogowych i lotniskowych z wykorzystaniem zaawansowanych badań dynamicznych. Przegląd Komunikacyjny, 2015, LXX, 10, 14-16.

[5] Machelski Cz., Mackiewicz P., Szydło A. Wykorzystanie stalowych płyt do uprawnienia przejazdu nad wykopami. Przegląd Komunikacyjny, 2015, LXX, 10, 2021.

[6] Szcześniak W. Analiza dynamiczna płyty o średniej grubości. Prace Naukowe PW, Budownictwo 1988, z.101, 1-236. 
[7] Szcześniak W. Drgania płyt. Dynamiczne obliczenia nawierzchni drogowej. IBDiM, Warszawa 2000.

[8] Szcześniak W. Drgania płyty o średniej grubości pod obciążeniem ruchomym. Rozprawy Inżynierskie IPPT PAN, 1985, 3, 1-2, 37-53.

[9] Szcześniak W. Wpływ dwuparametrowego podłoża sprężystego na drgania własne płyty o średniej grubości. Rozprawy Inżynierskie IPPT PAN, 1989, 37, 1, 87-115.

[10] Szcześniak W. Wybrane zagadnienia z dynamiki płyt. OW PW, Warszawa 2000.

[11] Wang Y.H., Tham L.G. and Cheung Y.K. Beams and plates on elastic foundations: a review. Structural Analysis and CAD. Prog. Struct. Engeng. Mater., 2005, 7, 174-183. 